\title{
DOS MODOS DE LEGISLAR RARIDADES EM PAUTA: REFLEXÕES ETNOGRÁFICAS SOBRE A CONSTRUÇ̃̃O DE UMA POLÍTICA NACIONAL PARA DOENÇAS RARAS NO CONGRESSO NACIONAL ${ }^{1}$
}

\author{
VICTOR CEZAR DE SOUSA VITOR
}

\begin{abstract}
RESUMO
Apresento reflexões com base em etnografia realizada entre maio de 2017 a outubro de 2018, adotando como tema central o campo de moralidades produzido a partir de práticas ativistas pelo direito à vida de pessoas vivendo com doenças raras no Congresso Nacional brasileiro. Mais precisamente, busco evidenciar certos padrões de responsabilidades e de julgamentos ético-morais emergidos da interlocução entre agentes do Estado, representantes de associações de pacientes com doenças raras e de indústrias farmacêuticas, durante 0 processo de adaptação, à gramática estatal, de demandas de uma causa coletiva como uma pauta legislativa. 0 contexto dos debates teve como pano de fundo tanto os discursos de defesa da causa coletiva construída por pacientes, familiares e associações de doenças raras em prol do "direito a tratamento como direito à vida" (Flores, 2016), assim como o discurso de gestores públicos do Ministério da Saúde acerca da reserva do possível.
\end{abstract}

\section{PALAVRAS-ChAVE}

Doenças raras; Causa coletiva; Pauta legislativa; Dilemas de gestão; Moralidades.

\section{THE WAYS OF LEGISLATING RARITIES ON THE AGENDA: ETHNOGRAPHIC REFLECTIONS ON THE CONSTRUCTION OF A NATIONAL POLICY FOR RARE DISEASES IN THE NATIONAL CONGRESS}

\begin{abstract}
Here I present reflections based on an ethnography conducted between may/2017 to october/2018, adopting as central theme the field of moralities produced from practices activists for the right to life of people living with rare diseases in the National Congress brazilian. More precisely, I seek to highlight certain standards of ethicalmoral judgments and responsibilities emerged from the interlocution between State agents, representatives of associations of patients with rare diseases and pharmaceutical industries, during the Process of adaptation, to "state gramar", of demands of a collective cause as a legislative agenda. The context of the debates had as elements both the discourses of defense of the collective cause built by patients, relatives and associations of rare diseases in favor of the "right to treatment as a right to life" (Flores, 2016), as well as the discourse of managers Ministry of Health's public opinion on the notion of reserve of the possible.
\end{abstract}

\section{KEYWORDS}

Rare diseases; Collective cause; Legislative agenda; Management dilemas; Morals.

\footnotetext{
${ }^{1}$ Este artigo é fruto de pesquisa de campo financiada com recursos do Conselho Nacional de Pesquisa e Desenvolvimento (CNPq), durante período de mestrado no Programa de Pós-graduação em Antropologia Social da Universidade de Brasília (PPGAS/UnB). Agradeço à professora e orientadora Soraya Fleischer e aos colegas do grupo de orientação coletiva pelas contribuições valiosas durante as versões preliminares deste artigo. Agradeço também as pareceristas do referido dossiê pela receptividade ao texto e pelas contribuições adicionais através dos pareceres.
} 


\title{
LES MOYENS DE LÉGIFÉRER SUR LES RARETÉSÀ L'ORDRE DU JOUR: RÉFLEXIONS ETHNOGRAPHIQUES SUR LA CONSTRUCTION D'UNE POLITIQUE NATIONALE POUR LES MALADIES RARES AU CONGRĖS \\ NATIONAL
}

\begin{abstract}
RÉSUMÉ
Je présente des réflexions basées sur une ethnographie menée entre mai 2017 à octobre 2018, en adoptant comme thème central le domaine des moralités produites par les militants des pratiques pour le droit à la vie des personnes vivant avec des maladies rares au Congrès National brésilien. Plus précisément, je cherche à mettre en évidence certaines normes de jugements éthiques-moraux et les responsabilités issues de la interlocution entre les agents de l'État, les représentants des associations de patients souffrant de maladies rares et les industries pharmaceutiques, au cours de la processus d'adaptation, de "grammaire de l'état", d'exigences d'une cause collective en tant qu'ordre du jour législatif. Le contexte des débats a eu comme éléments à la fois les discours de défense de la cause collective construite par les patients, les parents et les associations de maladies rares en faveur du "droit au traitement comme un droit à la vie" (Flores, 2016), ainsi que le discours des gestionnaires L'opinion publique du ministère de la santé sur la notion de réserve du possible.
\end{abstract}

\section{MOTS-CLÉS}

Maladies rares; Cause collective; Ordre du jour législatif; Dilemme de la gestion; Morale.

\section{LAS FORMAS DE LEGISLAR LAS RAREZAS EN LA AGENDA: REFLEXIONES ETNOGRÁFICAS SOBRE LA CONSTRUCCIÓN DE UNA POLITICA NACIONAL PARA LAS ENFERMEDADES RARAS EN EL CONGRESO NACIONAL}

\section{RESUMEN}

Presento reflexiones basadas en una etnografía llevada a cabo entre el 2017 de mayo y el 2018 de octubre, adoptando como tema central el campo de moralidades producidos a partir de prácticas activistas por el derecho a la vida de las personas que viven con enfermedades raras en el Congreso Nacional brasileño. Más concretamente, busco resaltar ciertos estándares de juicios y responsabilidades ético-morales surgidos de la interlocución entre agentes del estado, representantes de asociaciones de pacientes con enfermedades raras e industrias farmacéuticas, durante el Proceso de adaptación, a la gramática del estado, de demandas de una causa colectiva como agenda legislativa. El contexto de los debates tuvo como elementos tanto los discursos de defensa de la causa colectiva construidos por los pacientes, parientes y asociaciones de enfermedades raras a favor del "derecho al tratamiento como derecho a la vida" (Flores, 2016), así como el discurso de los directivos Opinión pública del Ministerio de salud sobre la noción de reserva de lo posible.

\section{PALABRAs CLAVE}

Enfermedades raras; Causa colectiva; Agenda legislativa; Dilemas de la gerencia; Moral. 


\section{INTRODUÇÃO}

Basta uma breve consulta entre projetos e matérias nos arquivos do legislativo federal brasileiro para constatar o recente surgimento do debate sobre o direito ao acesso a medicamentos e tratamentos para doenças raras2 no Congresso Nacional. Como pauta legislativa ${ }^{3}$, o tema surgiu primeiramente na Câmara dos Deputados, no ano de 2011, a partir do Projeto de Lei (PL) n 1606/2011 de autoria do então deputado federal Marçal Filho (PMDB/MS). Segundo a matéria, o objetivo principal foi dispor "sobre a dispensação de medicamentos para doenças raras e graves, que não constam em listas de medicamentos excepcionais padronizadas pelo Sistema Único de Saúde - SUS"4. Já no Senado Federal, foi no ano de 2013 que a temática sobre o acesso a medicamentos para doenças raras entrou em pauta, através do Projeto de Lei do Senado (PLS) n 530/2013, de iniciativa do senador e médico Vital do Rêgo (PMDB/PB). A proposta procurava instituir uma Política Nacional para Doenças Raras no SUS, sob um "regime diferenciado de avaliação, registro e importação de medicamentos órfãos" (RIBEIRO, 2015, p. 16).

Passados três anos, outra ação legislativa com o mesmo tom entrou em pauta no Senado Federal. Identificada como Projeto de Lei da Câmara (PLC) $n^{\circ}$ 56, de 2016, a matéria também buscava instituir uma Política Nacional para Doenças Raras no Sistema Único de Saúde (SUS). No entanto, trazia como diferencial o incentivo ao "acesso aos tratamentos disponíveis no mercado, inclusive por meio de mecanismos diferenciados para o registro sanitário e a incorporação de medicamentos órfãos, no SUS" ${ }^{5}$. O projeto tem como origem o já citado PL 1606/2011 da Câmara dos Deputados, matéria esta que inaugurou a temática

\footnotetext{
2 Segundo dados da Organização Mundial da Saúde (OMS), em perspectiva epidemiológica, configuram-se como doenças raras patologias crônicas que afetam até 65 pessoas a cada 100 mil indivíduos (1,3/2.000). Dentre cerca de 8.000 doenças raras existentes no mundo, cerca de $80 \%$ são genéticas e $20 \%$ são infecciosas. Em grande parte, trata-se de cronicidades de longa duração, degenerativas, incuráveis e de acesso difícil a diagnósticos e a tratamentos (farmacológicos ou paliativos) gratuitos.
}

${ }^{3}$ Saliento de antemão como procurei textualizar as distinções terminológicas traçadas ao longo do texto. Os termos em itálico são categorias êmicas agenciadas por interlocutores e trechos de discursos citados na íntegra. Os termos entre "aspas" são conceitos teóricos; ou seja, termos aproximados ao tema de pesquisa, mas não necessariamente presentes integralmente nos dados etnográficos desta. Já as categorias de pensamento, também em itálico, são justamente fruto do esforço de imbricação entre categorias êmicas e teoria antropológica trazida pela revisão bibliográfica e em negociação ao longo da textualização do campo.

\footnotetext{
${ }^{4}$ Projeto de Lei completo disponível em: 018643.proposicoesWeb2?idProposicao $=509247 \&$ ord $=0 \&$ tp=completa

${ }^{5}$ Documento Avulso inicial da matéria lida em Plenário do Senado Federal.

Disponível em:

https://legis.senado.leg.br/sdleg-

getter/documento?dm=3861060\&ts=1543015744591\&disposition=inline
}

http://www.camara.gov.br/proposicoesWeb/prop imp;jsessionid=92DB0406703C1965BE27532AAF 
como pauta no Congresso Nacional. Até o presente momento, o PL 1606/2011 encontra-se aprovado pelo Plenário do Senado desde outubro de 2018 e com indicação de retorno a sua Casa de origem, a Câmara dos Deputados, devido as alterações realizadas ao longo de sua tramitação no Senado Federal.

\section{$* * *$}

Foi partindo dessa recente trajetória legislativa, descrita acima sem as nuances congressistas que possivelmente a conformou, que parte do percurso de um estudo etnográfico sobre direito à vida e políticas de acesso a medicamentos e tratamentos tidos pela narrativa estatal como de alto custo ${ }^{6}$ ganhou forma. Desse estudo, textualizo algumas de suas discussões no presente artigo, adotando como tema central o campo de moralidades produzido a partir de demandas pelo direito à vida de pessoas vivendo com doenças raras no Congresso Nacional. Mais precisamente, busco evidenciar certos padrões de responsabilidades e de julgamentos ético-morais emergidos da interlocução entre agentes do Estado (parlamentares e gestores públicos em saúde), representantes de associações de pacientes com doenças raras e de indústrias farmacêuticas, durante o processo de adaptação de demandas de uma causa coletiva como uma pauta legislativa.

Como ambiente etnográfico, me refiro a sessões públicas deliberativas - ambientes institucionais estes de tomada de decisões colegiadas -, da Subcomissão de Doenças Raras (CASRARAS), integrada a Comissão de Assuntos Sociais (CAS/Senado Federal). Oficialmente, a Subcomissão esteve responsável por debater e instituir como Lei uma Política Nacional para Doenças Raras que garantisse legalmente diretrizes básicas para cuidados, tratamentos e medicamentos de alto custo, no âmbito do Sistema Único de Saúde (SUS). Acompanhar o percurso de tal projeto de Política Nacional tornou-se imprescindível ao passo em que tais audiências e reuniões públicas representam, na perspectiva de pacientes, familiares e associações, "instâncias privilegiadas de diálogo para discussão de temas que possam ter implicações mais profundas na legislação ou nos interesses da sociedade civil" (NASCIMENTO; DE PAULA, 2010 apud CASTRO, 2012). Tal aspecto se conjuga a conformação de um contexto de disputas por legitimidade dos discursos, do agenciamento de valores morais na construção de "verdades" (TEIXEIRA, 2014) e da formação de alianças e bases de apoio congressista, tendo em vista que, ao menos para parlamentares, "mentir ou omitir fatos é parte do jogo a ser jogado, como é o caso da vida política" (TEIXEIRA, 2014, p. 40).

\footnotetext{
${ }^{6}$ Segundo Vinhas de Souza, Krug, Picon e Schwartz (2010), apesar de não haver consenso sobre o conceito de "medicamentos de 'alto custo'" no Brasil, em relatório produzido pelo Ministério da Saúde (2002) o conceito se refere a produtos farmacêuticos "cujo valor unitário mensal esteja acima de um salário mínimo, ou medicamentos de uso crônico indicado para doenças muito prevalentes (acima de $1 \%$ da população) cujo custo mensal seja superior a um terço de um salário mínimo" (p. 3450).
} 
Foi neste contexto político-institucional que o acompanhamento etnográfico junto a associações de pacientes se tornou pertinente. Pertencentes ao terceiro setor, essas organizações são identificadas em um limiar de práticas que as predispõem em um campo de incertezas e suspeitas governamentais sobre a licitude das demandas. Tal predisposição, atribuída e sinalizada pelas associações, se deve em grande medida pelas mesmas "não terem fins lucrativos, sem serem necessariamente filantrópicas; serem políticas, sem serem partidárias; e serem não-governamentais, mas, eventualmente, manterem relações de cooperação com governos" (RAMOS, 2004, p. 1068). Além desses aspectos, presumo que a própria sensação de incerteza, "como uma característica central nas experiências de doença" (ATKINSON, 1995; KATZ, 1964 apud SABALA, 2011, p. 20) - sinalizada pela gestão pública acerca do custo-efetividade ${ }^{7}$ do investimento público empreendido - é um elemento central utilizado indiretamente por gestores como um risco contingencial que justifica inoperâncias em tomada de decisões governamentais em saúde pública voltadas para doenças raras. Sendo assim, descrevo aqui algumas das estratégias de convencimento e articulação exercidas por pacientes, familiares e associações, em um universo político-institucional de alianças, de trocas e de correlação de forças entre parlamentares, gestores em saúde e indústria farmacêutica, centrado na produção de leis, discussão de projetos e atendimento às bases eleitorais (BEZERRA, 1999).

Em síntese, creio que tal contexto legislativo, tido geralmente como engrenagem central para o exercício de poder legal e para a manutenção de direitos e deveres estatais, torna-se um solo fértil para o surgimento e análise de "controvérsias" (CASTRO, 2012). Isso, junto a uma série de debates já sinalizados por Petryna (2011) e pelos estudos das biossocialidades, acerca de "novas tecnologias gerarem novos contextos de decisão quanto aos procedimentos justos" (FilSCHER, 2003; RABINOW, 2003 apud PETRYNA, 2011). Além da produção de perspectivas ético-morais sobre o que são e como são definidas tomadas de decisões tidas como justas no campo da saúde pública, compreendo também que tal debate está assentado na causa coletiva de pacientes vivendo com doenças raras como "geradora de novas condições humanas e eventos" (ibidem).

\section{SOBRE A NATUREZA DAS SESSÕES}

O estudo de onde falo concentrou-se no acompanhamento de fóruns de discussões (Interlegis/Senado Federal), audiências públicas no Senado Federal e reuniões de gabinete na referida Casa Legislativa, entre maio de 2017 a outubro de 2018. No entanto, para este artigo, me atenho somente a duas reuniões públicas de trabalho realizadas na Subcomissão

\footnotetext{
${ }^{7}$ Em termos gerais, trata-se de uma das variáveis farmacoeconômicas que compõe o modelo de Avaliação de Tecnologias em Saúde (ATS), utilizado em estudos avaliativos confeccionados pela Comissão Nacional de Incorporação de Tecnologias no SUS (CONITEC).
} 
de Doenças Raras (CASRARAS/Senado Federal), composta por parlamentares, representantes de associações de pacientes, gestores em saúde da Agência Nacional de Vigilância Sanitária (Anvisa) e da Comissão Nacional de Incorporação de Tecnologias no SUS (CONITEC) e representantes das indústrias de fármacos.

Dentre as demandas que ganharam maior destaque ao longo de tais sessões deliberativas, estiveram: ampliação do teste do pezinho, com detecção precoce de um número maior de pacientes com doenças raras; isenção de impostos sobre medicamentos de alto custo para doenças raras; revisão de normas estabelecidas pelo Ministério da Saúde, sobre compras públicas e prazos de medicamentos para doenças raras, com vistas a flexibilizá-las e evitar futuros desabastecimentos; capacitação de profissionais em serviços de saúde; acesso universal aos centros de referência em doenças raras; aperfeiçoamento da pesquisa clínica, junto a aprovação de normas específicas pela Anvisa; e o fortalecimento de mecanismos de fiscalização de políticas públicas em saúde pelos próprios usuários do SUS, como maior transparência e participação civil em decisões produzidas no âmbito da CONITEC.

O contexto de conformação dos debates teve como pano de fundo duas convicções em conflito: a defesa da causa coletiva construída por pacientes, familiares e associações de doenças raras, baseada na noção do "direito a tratamento como direito à vida" (Flores, 2016), frente a noção de reserva do possível ${ }^{\beta}$, empreendida por gestores públicos do Ministério da Saúde. Creio que ambos foram responsáveis por produzir, dentre outros elementos, o que chamo de dilemas de gestão pública em saúde, acerca do debate sobre incorporação e dispensação de medicamentos e tratamentos de alto custo para doenças raras no âmbito do sistema público de saúde brasileiro.

\section{OS MODOS DE LEGISLAR UMA CAUSA COLETIVA COMO UMA PAUTA LEGISLATIVA}

Tendo em vista as duas reuniões públicas da CASRARAS selecionadas para este artigo, me atenho aos resultados da análise de alguns aspectos que se destacaram ao longo de tais sessões. Mais precisamente, busco evidenciar como demandas por medicamentos e tratamentos de alto custo e denúncias de ineficiência na gestão pública em saúde - ambas evocadas por pacientes, familiares e associações - ganharam forma em deliberações legislativas, na presença de representantes das instituições (parlamentares e gestores) a serem convencidos, questionados e afetados pela causa coletiva.

\footnotetext{
${ }^{8}$ Salvo as diversas leituras na magistratura brasileira sobre o termo, a definição de reserva do possivel, frequentemente agenciada na gestão pública e adotada aqui, está associada a declaração de escassez ou insuficiência de recurso público orçamentário para assumir obrigações estatais que asseguram o mínimo existencial (necessidades básicas à dignidade da vida humana) a sujeitos de direitos.
} 


\section{DA PRESENÇA RETÓRICA DE MÉDICOS}

Durante os discursos iniciais de senadores integrantes da Subcomissão, notei recorrentes atribuições positivas à relação que alguns destes parlamentares mantinham com a formação biomédica. Nas primeiras falas, ganhou nitidez a busca por atribuir competência e qualificação a Subcomissão CASRARAS em função de seu presidente e seu relator serem médicos de formação. Observei que tais destaques foram uma deixa para que, em alguns momentos, ambos os parlamentares acionassem a formação acadêmico-biomédica e as práticas científicas que tal formação pressupunha, para fundamentarem seus discursos. Compreendi que, ao papel de mediação parlamentar, foi acrescido o papel de validação ${ }^{9}$ de informações próprias da prática biomédica, como mais um elemento de legitimidade atribuído aos mesmos na produção e na condução dos debates. Obtiveram não somente o exercício de poder mediador, comumente atribuído ao exercício parlamentar em sessões plenárias de comissões, mas também o exercício de poder argumentativo de validação de procedimentos e condutas biomédicas, em um tom generalista.

No entanto, mesmo com a atribuição positiva sobre o conteúdo discursivo de ambos os parlamentares médicos, em alguns momentos ficou evidente no teor de suas colocações a predominância do desconhecimento sobre doenças raras no campo biomédico. Tal desconhecimento e ausência de especialização foi assumida por um dos parlamentares médicos em uma das reuniões, ao atribuir reconhecimento ao papel das mães no processo de diagnóstico e tratamento dos filhos. Em suas palavras, me desculpem os colegas [profissionais da medicina], mas as mães, hoje, e os pais, muitas vezes conseguem diagnosticar uma criança que tem a mesma doença, às vezes muito mais ágil do que o próprio colega médico. Isso eu não estou dizendo para comprometer a nossa classe não. Porque existem peculiaridades em cada uma dessas patologias. E a variedade é enorme. Dentro mesmo da área de atuação de geneticistas tem muitos que não conhecem patologias existentes. Porque é uma matéria complexa.

Por certo, o referido discurso sobre o papel das mães, utilizado por diversas vezes por agentes institucionais (parlamentares, gestores públicos em saúde e representante de indústrias farmacêuticas), fazia parte de um repertório ativista amplamente conhecimento e defendido pelas associações de pacientes. Aqui, se por um lado temos o agenciamento desses fragmentos por agentes institucionais expressando a influência que a causa coletiva opera nestes agentes, por outro lado, episódios como esse expressavam também o quanto tais agentes compreendem e antecipam retoricamente as especificidades do repertório de

\footnotetext{
9 Sobre as similaridades entre as retóricas políticas e científicas, ver "The Manufacture of Knowledge, An Essay on the Constructivist and Contextual Nature of Science" de Karin Knorr-Cetina (1981).
} 
demandantes por direitos com os quais buscam criar empatia e evidentemente administrar reações.

Notei que tal atribuição positiva surgiu desacompanhado da publicização de outros desafios do cuidado durante a centralização de demandas ao papel de mãe. Aureliano (2018) em recente artigo, nos conta sobre o quanto tem recaído nas mulheres "uma grande carga moral, econômica e emocional relacionada ao cuidado do paciente com doença rara hereditária" (p. 377). Em grande medida, segundo Adriana Dias Higa (2018), nestes casos "as mães tornam-se protagonistas porque, em geral, 78\% dos homens saem de casa quando nasce uma criança com doença rara e/ou deficiência (p. 20). Ficou evidente, em tal artifício de antecipação utilizado por agentes institucionais, que quando o reconhecimento do cuidado rotineiro dedicado ao paciente era considerado como um valor a ser destacado, não havendo igual destaque para os próprios dilemas e dificuldades vividos por quem cuida, havia um reforço da noção de cuidado como um devir de responsabilização centrado, em grande parte, na figura materna. No entanto, como bem aponta Aureliano (2018), doenças raras hereditárias "acaba por afetar e envolver toda a família de diversas formas: o cuidado imediato do familiar afetado, a reorganização do espaço físico da casa, a preocupação com a própria saúde e a da prole, se ela já existir, e de demais parentes consanguíneos" (p. 372373). Creio que tal fator em torno de entes familiares como sujeitos políticos, apesar dos envolvimentos desiguais entre os diferentes papeis dentro do ambiente familiar, contribuiu para ativistas apostarem nessa categoria como ampliadora de redes de afetação e de engajamento alheio em sessões plenárias, tendo em vista os múltiplos papeis que ela possibilita acionar e afetar em cada agente institucional em sessão, proveniente de alguma família com histórico de patologia rara ou não.

\section{A SENSIBILIZAÇÃODA GESTÃO E A GESTÃODA SENSIBILIZAÇÃO}

Adiante, início uma análise sobre o dilema contido no ato de sensibilizar-se enquanto gestão pública em saúde, com base na observação de interações conflituosas entre associações de pacientes e gestores. Para tal, destaco o questionamento de uma das representantes de associações de pacientes a uma representante da CONITEC convocada pela CASRARAS.

No caso em questão, a alegação de gestores sobre a ausência de um relatório técnico comprovando a eficácia do aparelho respiratório de nome Cof Assist no Brasil, a ser anexado ao processo montado pela associação de pacientes demandante da incorporação do aparelho no SUS, foi marcado pela evidente precariedade de justificativas por parte de gestores presentes na sessão. Como resposta a possivel pendência documental, em tom burocrático e impessoal, foi reiteradamente alegado pela gestora e por demais colegas de 
gestão que há necessidade de que todas as documentações exigidas estejam incorporadas ao processo, para assim ser avaliada de fato.

Prosseguindo, a representante da associação de pacientes em questão buscou reforçar a sua indignação diante da ausência argumentativa dos gestores públicos em saúde, alegando com veemência que os documentos já estavam anexados ao processo. Neste interim, na medida em que a representante da associação afirmava que o processo de incorporação é bom para o paciente, é bom para o poder público e realmente a gente não consegue entender por que que essa tecnologia, insistentemente, não é incorporada, acentuavase um risco moral de gestores em insistirem em entraves burocráticos-institucionais como justificativa. Notei que em tais ocasiões, prosseguir em um conflito público com ativistas em audiências, principalmente se possuem relação familiar com a pessoa diagnosticada - ou mais ainda, sendo a demandante justamente quem vive com a doença - suscitava, a princípio, um risco moral de tais gestores serem taxados como agentes dotados de apatia e insensibilidade exercidas sob o véu de uma burocracia estatal. No entanto, ao passo em que a classificação de insensibilidade se tornava um risco eminente de reprovação direcionada a gestores, notei em contrapartida um dever destes em manter uma subjetividade específica diante de tais situações. O dever consistia em não transparecer uma sensibilidade excessiva ${ }^{10}$ diante das particularidades dos casos que compunham a causa - publicizadas sob formas de testemunhos de sofrimento de ativistas que denunciavam a inoperância estatal no processo de avaliação (Anvisa), incorporação e dispensação (CONITEC) de medicamentes e tratamentos pelo SUS -, mas também não parecer ${ }^{11}$ indiferente e resistente diante de tais evocações.

Além desse comportamento de gestores manter relação com um tipo de performance rotineira de fiscalização e identificação quase pericial de falsos demandantes no âmbito da administração pública, tal dever de impessoalidade na gestão ganhou ainda mais legitimidade institucional em um contexto de suspeitas ${ }^{12}$ de relações entre associações de pacientes e indústrias farmacêuticas, em processos de judicialização de medicamentos de alto custo. Foi evidente certo consenso circunstancial entre parlamentares, gestores públicos

\footnotetext{
${ }^{10}$ Sobre os limites assim como as possibilidades de produção cautelosa de uma empatia profissional e a afetação emocional gestada no funcionalismo público, ver Lugones (2012).

${ }^{11}$ Interessante notar que tal comportamento ganha sentido normativo segundo o próprio Código de Conduta da Alta Administração Federal (2014), ao dizer que "além de comportar-se de acordo com as normas estipuladas", o administrador público deve se atentar para "o decoro inerente ao cargo. Ou seja, não basta ser ético; é necessário também parecer ético, em sinal de respeito à sociedade" (p. 19). Link: file:///C:/Users/Victor\%20Cezar/Desktop/codigo-conduta-compilado-2014.pdf

${ }^{12}$ Em sessão posterior às analisas neste artigo, segundo a fala do então ministro Ricardo Barros, o orçamento direcionado pelo Ministério da Saúde a compras antecipadas de medicamentos de alto custo, anteriormente adquirido para o período de um ano, foi reajustado para um período menor este, não especificado pelo mesmo -, devido ao fato de que, segundo o ministro, "infelizmente, nem todas as liminares se sustentam".
} 
em saúde e defensor público sobre a judicialização dos medicamentos de alto custo ser uma prerrogativa de todo cidadão e um direito a assistência jurídica integral e gratuita. No entanto, a pauta do projeto de Lei de uma Política Nacional integral para medicamentos e tratamentos de doenças raras no âmbito do SUS, como forma de reduzir a busca por tal mecanismo jurídico, produziu certos constrangimentos morais em pacientes e representantes de associações em defende-la nos casos em que só restavam a judicialização como alternativa.

\section{O DIAGNÓSTICO PRECOCE}

A ampliação do teste do pezinho como medida de efetivação do diagnóstico precoce para doenças raras no âmbito do SUS foi uma das principais demandas levantadas por algumas das falas de representantes de associações de pacientes presentes nas sessões. Dentre os relatos, mais precisamente sobre os impasses financeiros informados pelos próprios gestores públicos do Ministério da Saúde, uma representante apontou a classificação custosa que tais gestores atribuem a incorporação do diagnóstico precoce no SUS, durante reuniões no Ministério. Em seguida, a mesma fez um paralelo entre o custo da ampliação do teste do pezinho, no âmbito do sistema público de saúde brasileiro, frente aos atuais gastos contraídos pelo Ministério da Saúde com processos judiciais envolvendo medicamentos e tratamentos de alto custo pela via estatal. Completou, a representante, que a partir do momento em que a gestão pública outorgar pela implementação do diagnóstico precoce no âmbito do SUS, uma família vai ter um curso natural da vida. Do seu ente modificada [palmas].

Já em outro momento da sessão, ficou evidente uma contradição denunciada por representantes de associações diante da mesma pauta sinalizada: a exigência de diagnóstico precoce via teste do pezinho - esta, uma política considerada pelos ativistas como ineficaz no país -, justamente como uma condição para a dispensação de alguns medicamentos, como é o caso da doença rara Mucopolissacaridose (MPS) tipo 2. Nas palavras da representante, como exigir um diagnóstico de até 12 meses se a própria estrutura [governamental] é incapaz de fornecer esse diagnóstico? Em resposta ao questionamento, segundo um dos gestores da CONITEC, os especialistas do órgão responsável pela formulação dos Protocolos Clínicos e Diretrizes Terapêuticas (PCDT) preconizam tal limite de tempo porque este é o prazo necessário para que o medicamento alcance o efeito esperado, haja vista que após 12 meses há um comprometimento neuronal que impossibilita a sua eficácia.

Retornando a justificativa anterior, ao passo em que gestores públicos em saúde declaravam a limitação do financiamento de ações comprometidas com a preservação do curso natural da vida como um tipo de contingência legítima da administração pública em saúde, como enfatizou uma das representantes de associações, surgiram duas questões 
morais que acompanharam todo o debate. A primeira diz respeito ao campo minado presente no risco de gestores públicos aproximarem fatalmente aspectos como estudos de avaliação econômica para custo-efetividade e a máxima do direito à vida, delimitando, assim, atos administrativos que incidem diretamente sob direitos fundamentais em detrimento do fator custo, como limitador de investimentos tidos como incertos. A segunda questão, como busca por suavizar tal risco dos dilemas de gestão, diz respeito tanto aos manejos discursivos da burocrática estatal, tido como produtor de distanciamento e de impessoalidade via fatiamento de responsabilizações governamentais ao longo do organograma ministerial, quanto aos descompassos entre a temporalidade estatal e do desenvolvimento de pesquisas científicas diante da temporalidade degenerativa de doenças raras, que demanda por urgência. Creio que ambas as questões são classificadas pela gestão pública como limitações contingências de difícil operacionalização estatal. Sendo assim justificadas tais limitações, agem como um precedente moral utilizado por gestores públicos diante do possível risco de serem alvos de formas de subjetivação individualizante expresso na responsabilização com a pauta pelo direito à vida.

Passando para o tópico seguinte, a partir da noção de ser propositivo, foi possível visualizar aspectos como o tipo de reconhecimento público destinado ao sofrimento comunicado publicamente pelos demandantes, em meio a tentativa de enquadrar tais linguagens ao formato legislativo preconizado pelos debates e as formas com que as expressões obrigatórias dos sentimentos (Mauss (1979 [1921]) e as expressões obrigatórias do regimento conviveram ao longo das sessões acompanhadas.

\section{ÉIMPORTANTE QUE, ALÉM DA FALA, VOCÊS COLOQUEM NO PAPEL: SER PROPOSITIVO}

Destaco a partir de então a noção de ser propositivo, instrumento regimental esse de mediação parlamentar que operou como uma prática de regulação das comunicações ao longo de ambas as sessões públicas acompanhadas. Tal prática, tida como máxima na mediação parlamentar, teve importância significativa para o controle de alguns discursos, tanto na limitação de seu conteúdo assim como na duração dos mesmos. Em ambas as sessões, notei que o tom imperativo e ambivalente no ato de exigir uma postura propositiva as falas, era predominantemente direcionado aos discursos proferidos por representantes da sociedade civil organizada; no caso, pacientes, familiares e representantes de associações.

Oficialmente, um percurso tipicamente propositivo descrito pelo parlamentar que presidia a Subcomissão, consistia em colocar demandas no papel, produzir um relatório e buscar a aprovação deste para torná-lo realidade. Uma lei. Já informalmente, para enquadrar os relatos de pacientes, familiares e associações em um tom propositivo característico da gramática estatal, o referido senador agenciava justamente o conteúdo do que se pretendia 
controlar em sessões - ou seja, um tom particularista do sofrimento relatado como testemunho. Tal agenciamento, sob discursos como eu sei por que eu já convivi e eu entendo a angústia de vocês (...) eu tenho isso [doença rara] em minha família, criava simultaneamente uma espécie de empatia ou sensibilização a causa coletiva, assim como uma tentava de atribuir aos relatos de sofrimento de pacientes um consenso de que tais informações já são de amplo conhecimento dos presentes e, consequentemente, de dispensável evocação. Além disso, a recomendação de colocar as demandas no papel foi um dos artifícios para a inibição de tais evocações públicas, por meio da transferência do exercício de síntese elemento este contido na postura propositiva - aos próprios sujeitos que comunicavam o sofrimento em testemunho.

Junto a esse artifício, ocupar alguns minutos das sessões para expor a experiência de sua família com a Doença de Huntington, como fez o senador que presidia a Subcomissão, tornou-se uma alternativa discursiva recorrente na busca por um tom propositivo aos debates encarregados de conduzirem a pauta das Raras. Creio que tal exposição concedeu um precedente que o legitimava moralmente delimitar testemunhos narrados por pacientes, familiares e representantes de associações. Como artifício de delimitação, criou-se uma espécie de profissional engajado, cujo efeito de mediação dos debates acionava uma imagem de empatia via reafirmação de uma experiência de doença já convivida (já perdi muitos tios, muitos primos em função de uma doença rara. Por isso que é uma coisa que me interessa). Sob o véu do profissionalismo engajado, tais relatos buscavam delimitar testemunhos de pacientes, familiares e representantes de associações. Isso, justamente através da imagem simultaneamente paternal e profissional comprometido com a causa, como um precedente moral que autorizava regular testemunhos, destituindo-se dos riscos oferecidos pela imagem de apatia profissional (então o que vossa senhoria está dizendo para mim é uma coisa que eu já convivi (...) Mas não pensem vocês que eu não vou ser firme na hora de ter que ser firme).

Somada aos elementos de empatia e de delimitação operacionalizados pelos parlamentares que presidiam e relatavam a referida Subcomissão, creio que a formação acadêmico-biomédica destes também trazia a validação científica já descrita como elemento de exercício de poder no controle da proposição. Tal elemento também potencializava a imagem do profissional engajado, devido a formação biomédica ser constantemente relegada, à princípio, a dimensão aliada de pacientes, familiares e associações de pacientes. Compreendi que essa imagem aliada foi constituída através do estatuto de confiança e de engajamento atribuído a geneticistas e demais médicos/pesquisadores do campo das doenças raras no Brasil, por estarem em constante contato com demandantes no aperfeiçoamento de tratamentos especializados. Papel este, em contraposição aos gestores públicos, geralmente considerados como produtores de entraves burocráticos às demandas. 
Ao passo que o tom propositivo delineava o discurso de representantes de associações de pacientes ao longo das sessões, por outro lado foi possível identificar a adaptação de suas próprias formas de reivindicação ao ambiente legislativo conformado por alianças, trocas e correlação de forças, acrescentando em seus discursos elementos que privilegiassem também possíveis interesses governamentais. Dentre as ocasiões, houveram reivindicações de dois representantes de associações que exploraram uma controvérsia entre investimentos em tratamentos e mercado de trabalho. Os representantes agenciaram, como argumento de incentivo a ampliação da incorporação de medicamentos para doenças raras no SUS, a contradição entre pacientes internados que não conseguem trabalhar e o custo altíssimo de internações para o SUS, diante da possibilidade de, ao serem tratados adequadamente, conquistariam autonomia motora para serem produtivos a sociedade. Aqui, como um incentivo a políticas de investimentos em tratamentos, ambos os representantes de associações se concentraram nos possíveis interesses governamentais em pessoas aptas a exercerem alguma função trabalhista remunerada, como efeito de reciprocidades diretas entre sociedade civil e governo, em um ambiente de convencimento da legitimidade de demanda por direitos.

Já aqueles sujeitos que demarcavam em seus discursos uma explicação racionalizada da burocrática estatal (parlamentares, representante de indústrias farmacêuticas e principalmente gestores públicos em saúde), ao si apropriarem de discursos cujo conteúdo trazia consigo o reconhecimento do sofrimento alheio - em um tom de compaixão a causa em pauta -, não eram controlados ou interrompidos pelo mecanismo da proposição, adotado pela mediação parlamentar sob pacientes, familiares e alguns ${ }^{13}$ representantes de associações. Creio que tal precedente se expressou de formas diferentes em cada tipo de agente institucional ao reconhecerem o sofrimento sinalizado durante a fala de demandantes sob uma gramática congressista caracterizada pela dimensão da "responsabilidade qualificada em termos posicionais" (TEIXEIRA, 1999) e expressada em função das expectativas de trocas ${ }^{14}$ estabelecidas na institucionalidade.

Levando novamente em consideração o contexto de suspeitas nas relações entre associações de pacientes e indústrias farmacêuticas, implicitamente presente nas sessões,

\footnotetext{
${ }^{13}$ Aqui, pondero que a utilização do tom propositivo insidia somente sobre alguns representantes de associações de pacientes. Isto, por notar que quanto mais uma associação detinha reconhecimento institucional, geralmente remetida àquelas associações de grande porte e de reconhecimento nacional, mais detinham legitimidade e precedente para discursar de forma discricionária ao longo das sessões.

${ }^{14}$ Sobre a noção de "troca" no ambiente Congressista, Abreu (2005) afirma que em tais interações, há ausência de uma regra rígida que estabeleça tanto o que é "valioso trocar" assim como "com quem se deve ou se é preferível trocar" (p. 343). Aqui, o mesmo autor defende que "o momento, o cálculo (equivocado ou não), as ambições e as estratégias regulam o que é importante, valioso ou mesmo essencial e com quem seria melhor trocar" (p. 351).
} 
notei que havia uma espécie de cautela por parte de gestores públicos, diante de um suposto risco moral em se deixar convencer pela via do sofrimento comunicado por quem demanda por urgência no acesso ao tratamento. Tal risco somente era combatido pelo mecanismo da proposição nos casos em que a autoria da comunicação do sofrimento era algum representante da sociedade civil organizada. Já a ausência de regulação propositiva àqueles que possuíam status de agentes institucionais, justificava-se em tal contexto devido a desvinculação e remanejamento emocional (próprios do engajamento profissional), à priori, atribuída aos mesmos e seguida como uma espécie de compromisso de distanciamento profissional como princípio naturalizado na administração pública. Em contrapartida, notei que tal exercício de desvinculação, consequentemente, sofreu certos constrangimentos morais, reificados como uma expressão obrigatória de sensibilizar-se diante da experiência de sofrimento que implicava o outro, demandante por direitos. Instaurava-se, então, um dilema que operava de algum modo em todos, entre o ato de constranger moralmente uma possível demonstração de apatia de gestores públicos (o constrangimento pela sensibilização, tida como obrigatória) e o ato de constranger pelo dispositivo regulador da proposição parlamentar (o constrangimento da sensibilização tida como excessiva).

Tal dilema tinha como contexto o ambiente legislativo operacionalizado também como uma possibilidade de "escuta" (FASSIN, 1998) do testemunho e consequentemente da socialização de particularidades de doenças raras desconhecidas e subnotificadas, para além dos dispositivos de proposição que a normatizava. Tal escuta, em um ambiente deliberativo amplamente televisionado, taquigrafado, midiatizado e envolto por agentes institucionais, possibilitava, na perspectiva de tais pacientes, familiares e representantes de associações, a tradução à gramática estatal de condições tidas tradicionalmente como desconhecidas e exceções biomédicas, para ultrapassar justamente a relação de violência institucional expressada pela negação do reconhecimento de necessidades comunicadas por tais vivências.

\section{CONSIDERAÇÃO FINAIS: A EXCLUSÃONA INCLUSÃOE OS DILEMAS DA CAUSA COMO PAUTA}

A partir dos registros de campo de duas sessões públicas selecionadas para este artigo, iniciei uma análise dos processos de exclusão de alguns valores da causa coletiva, justamente no contexto de inclusão de uma Política Nacional de Doenças Raras no SUS como pauta legislativa no Senado Federal. Desde então, pude acompanhar o estabelecimento das formas de se comunicar o sofrimento e a urgência por pacientes, familiares e associações, em um contexto legislativo composto por diversos agentes institucionais e seus interesses transversalizados na produção de tal pauta. 
Neste contexto de produção de uma pauta em deliberação, marcado por ritos regimentais, observei relações cautelosamente diplomáticas entre Executivo (Ministério da Saúde) e Legislativo (parlamentares integrantes da Subcomissão CASRARAS), de manutenção de bases político-partidárias e de busca por (re)elegibilidade parlamentar. Tais relações enquadravam demandantes em uma espécie de sofrimento adequado a ser publicizado, na medida certa, buscando conter a potência pública da comunicação do testemunho em primeira pessoa, encarado em alguns momentos como apelativo e pejorativamente persuasivo. Creio que essa forma de "decoro" era defendida pela mediação parlamentar através do mecanismo regimental da proposição, sob efeito similar a aplicada aos demais parlamentares, como "censura verbal" (TEIXEIRA, 1999). Porém, a regulação que recaia sobre pacientes, familiares e alguns representantes de associações, егa regida sob uma lógica específica de contenção disciplinadora de excessos das sensibilidades publicizadas em plenário. Tal comportamento era encarado como um pressuposto atribuído particularmente a estes sujeitos, devido a aspectos como desobrigação de dominarem etiquetas regimentais; o anseio pela legitimação da urgência de um bem público fundamental; e as suspeitas morais diante do exercício de persuasão que tais formas de comunicar o sofrimento operariam em uma "instituição prestigiosa" (TEIXEIRA, 2014) de fiscalização do Poder Executivo, como o Senado Federal.

Sobre as formas com que gestores procuravam criar uma blindagem moral diante da afetação sentimental da causa pelo direito à vida, creio que estas sinalizavam para reflexões de como situações de sofrimento, comunicadas publicamente, alcançavam reações éticomorais de responsabilização pública de gestão, que exigiam soluções imediatas e demais formas de engajamento alheio ${ }^{15}$. Algo similar aos "sentimentos morais" referenciados por Fassin (2012), como a potencialidade com que afetações emocionais conectam, ao menos profissionalmente, tais agentes públicos ao mal-estar alheio, incitando assim disposições para soluciona-lo.

Diante da gramática coercitiva da proposição, a demanda comunicada por pacientes, familiares e associações deveria se inscrever nas sessões de forma que não fossem tão "brandas", correndo o risco de serem encaradas como demandas não emergenciais e sendo assim colocadas em segundo plano governamental, e nem muito "excessivas" a ponto de serem classificadas pela gestão pública como inoperantes pelo governo, diante da reserva do possível das contas públicas. Creio que o dilema ético-moral evocado pela noção de reserva do possivel diz respeito tanto a possibilidade de utilização do mesmo por gestores públicos de forma generalista, legitimando o descumprimento de obrigações estatais, assim como a dificuldade jurídica e de gestão pública em estabelecer quais são os parâmetros responsáveis

\footnotetext{
${ }^{15}$ Sobre as formas de agenciamentos e reconhecimentos do "sofrimento alheio", me inspiro em “Distant Suffering" (1999 [1993]), de Luc Boltanski.
} 
por definir necessidades básicas e quais os recursos personificados como fundamentais, invioláveis e assim responsáveis por definir a própria ideia de mínimo existencial, de garantia estatal.

Já o sofrimento comunicado por parlamentares, ao falarem em nome de pacientes e familiares, recebia maior credibilidade institucional a tal urgência comunicada, em comparação a baixa atenção atribuída ao sofrimento comunicado por algumas das associações de pacientes. Assim, para ter eficácia de convencimento público, notei que havia a necessidade de tal sofrimento ser comunicado em terceira pessoa institucional. Mais precisamente, pelo profissional responsável por operar uma "conversão ou 'transporte' do reconhecimento ou observação empírica do sofrimento para o plano da generalidade 'política', pela ação à distância que o enfrentamento com o fato do sofrimento impõe" (DUARTE, 1996, p. 166). É necessário destacar também que tal noção de "distância", como uma impessoalidade que "constitui o pano de fundo da institucionalidade pública moderna" (DUARTE, 1996, p. 164), não poderia ser confundida com apatia frente ao sofrimento alheio, mas sim uma garantia de desvinculação do agente institucional a possíveis interesses mercantis atribuídos ao campo de suspeitas das relações entre indústrias farmacêuticas e associações de pacientes. Assim, a postura adotada por pacientes, familiares e representantes de associações, reconhecendo uma série de ônus decorrentes dos processos de judicialização de medicamentos de alto custo no campo da saúde pública, tornou-se necessário para que tais demandantes fossem encarados como agentes qualificados para um debate legislativo envolvendo a institucionalização de uma Política Nacional que inibisse a necessidade da judicialização como um instrumento recorrente de demanda por direitos.

Por fim, creio que a prática da judicialização sendo taxada simultaneamente como um procedimento individualizante de demandas por direitos e como uma brecha à capitalização operada pela indústria de fármacos - em comparação a criação de uma Política Nacional como sinônimo de coletivização e ampliação do acesso à saúde -, revelou um campo de polarização moral entre direitos individuais (sob argumentação do mínimo existencial) e coletivos (sob argumentação da reserva do possivel). Neste campo de gestão pública, prevalecia uma visão de justiça coletiva como ideal, tornando moralmente arriscado a explicitação pública do sofrimento individual e de argumentações contrárias a generalidades estabelecidas em políticas de tratamento, indiretamente fomentadas por tal visão e indiferentes a especificidades demandadas pelos pacientes com doenças raras. Diante de tal polarização, estabelecer e manter a pauta das raras em deliberação (e, posteriormente, em tramitação), ao longo de sessões plenárias em Comissões e Subcomissões do Congresso Nacional, se tornou o próprio meio prático de socialização e de visibilidade política das raridades desassistidas e de suas urgências. Isto, por meio da "escuta" 
institucional angariada pela causa coletiva, visando possibilidades outras de acesso à saúde para além da própria temporalidade normativa do universo legislativo.

\section{REFERÊNCIAS}

ABREU, Luiz Eduardo. L. A troca das palavras e a troca das coisas. Política e linguagem no Congresso Nacional. Mana (UFRJ. Impresso), Rio de Janeiro, v. 11, n.1, p. 329-356, 2005. http://dx.doi.org/10.1590/S0104-93132005000200001

AURELIANO, Waleska. A. Trajetórias Terapêuticas Familiares: doenças raras hereditárias como sofrimento de longa duração. Ciência \& Saúde Coletiva, p. 369-380, v. 23, 2018. http://dx.doi.org/10.1590/1413-81232018232.21832017

BEZERRA, Marcos Otavio. Em nome das "bases": política, favor e dependência pessoal. Rio de Janeiro: Relume Dumará: Núcleo de Antropologia da Política, 1999.

BOLTANSKI, Luc. Distant Suffering: morality, media and politics. Cambridge: Cambridge University Press. 1999.

CASTRO, Rosana. No fiel da balança: uma etnografia da regulamentação sanitária de medicamentos para emagrecer. (Mestrado em Antropologia Social). Programa de Pós-Graduação em Antropologia Social. Departamento de Antropologia. Universidade de Brasília, 2012.

DUARTE, Luiz Fernando. D.. Distanciamento, reflexividade e interiorização da Pessoa no Ocidente. A propósito de La Soufrance à Distance. Morale humanitaire, médias et politique, 1993 - Boltanski, Luc; Paris: Editions Métailié. Mana (Rio de Janeiro), Rio de Janeiro, v. 2, n.2. pp. 163-176, 1996 http://dx.doi.org/10.1590/S0104-93131996000200007

FASSIN, Didier. Humanitarian Reason: a moral history of the present. Berkeley, Los Angeles, London: University of California Press, 2012.

FLORES, Lise. V. "Na minha mão não morre": uma etnografia das ações judiciais de medicamentos, Dissertação de Mestrado em Antropologia Social no Programa de Pós-Graduação em Antropologia da UFPR, 2016.

HIGA, Adriana D. "Prefácio: Algumas palavras sobre mães raras..." In: NOVAES, Désirée. Mães Raras, essas mulheres fortes. Editora Polen Livros: São Paulo, 2018.

KNORR-CETINA, Karin. The Manufacture of Knowledge, An Essay on the Constructivist and Contextual Nature of Science. Oxford: Pergamon Press. 1981.

LUGONES, María Gabriela. Obrando en autos, obrando en vidas: formas e fórmulas de Proteção Judicial dos tribunais Prevencionais de Menores de Córdoba, Argentina, no começo do século XXI. Tese de doutorado. Programa de Pós-Graduação em Antropologia Social, Museu Nacional, da Universidade Federal de Rio de Janeiro, 2012.

MAUSS, Marcel. A expressão obrigatória dos sentimentos. In: OLIVEIRA, Roberto Cardoso (org.). Antropologia. São Paulo: Ática, 1979. p. 147-153. 
PETRYNA, Adriana. Experimentalidade: ciência, capital e poder no mundo dos ensaios clínicos. Horiz. antropol. [online], v.17, n.35, 2011. http://dx.doi.org/10.1590/S0104-71832011000100005

RAMOS, Sílvia. 0 papel das ONGs na construção de políticas de saúde: a Aids, a saúde da mulher e a saúde mental. Ciênc. saúde coletiva [online], v.9, n.4, 2004. http://dx.doi.0rg/10.1590/\$1413$\underline{81232004000400027}$

RIBEIRO, Bruna Cruz. Judicialização de medicamentos órfãos: o papel de mediador do Poder Legislativo. Monografia (Bacharelado em Ciência Política), Universidade de Brasília, Brasília, 2015.

SABALA, Joana Z. Incerteza, estratégias e construção do self nas doenças raras [Em linha]. Lisboa: ISCTE-IUL. Dissertação de mestrado, 2011.

SOUZA, Mônica Vinhas de; KRUG, Bárbara Corrêa; PICON, Paulo Dornelles; SCHWARTZ, Ida; DOEDERLEIN, Vanessa. Medicamentos de alto custo para doenças raras no Brasil: 0 exemplo das doenças lisossômicas. Ciênc. saúde coletiva [online], p. 3443-3454, 2010. http://dx.doi.org/10.1590/S1413$\underline{81232010000900019}$

TEIXEIRA, Carla C.. 0 Preço da Honra. Série Antropologia, Brasília, DF, n.255, p. 1-27, 1999. Disponível em: http://dan.unb.br/images/doc/Serie253empdf.pdf. Acesso em: maio de 2019.

TEIXEIRA, Carla C. Pesquisando instâncias estatais: reflexões sobre o segredo e a mentira. In: CASTILHO; SOUZA LIMA, Antônio Carlos; TEIXEIRA, Carla C.. (Org.). Antropologia das Práticas do Poder: reflexões etnográficas entre burocratas, elites e corporações. v. 1, 1ed. Rio de Janeiro: 2014. p. 33-42. 